\title{
Health-Seeking Behavior and Quality of Life of Patients with Diabetes Mellitus in Iloilo, Philippines
}

\author{
Perry Paul J. Espinosa ${ }^{1 *}$ and Mae Joy P. Espinosa ${ }^{2}$ \\ ${ }^{1}$ Woosong College, Daejeon, Republic of Korea \\ ${ }^{2}$ Woosong University, Daejeon, Republic of Korea \\ 'paulespinosa721@gmail.com, ${ }^{2}$ maejoyespinosa426@yahoo.com
}

\begin{abstract}
This study was conducted to determine the health-seeking behavior and quality of life of patients with diabetes mellitus. The respondents of the study were the 45 patients with diabetes mellitus who came in for consultation in a Diabetic Resource Clinic of a Government Hospital in Iloilo, Philippines. The respondents' health-seeking behavior was good and their quality of life was satisfactory. The results indicate statistically significant relationship between the preventive and the curative health-seeking behaviors and quality of life of patients with diabetes mellitus.

Appropriate health-seeking behaviors in terms of preventive and curative aspects are important factors that could improve the quality of life of patients with diabetes mellitus. Results from this study suggest strategies to enhance health-seeking behavior in the promotive and rehabilitative aspects.
\end{abstract}

Keywords: Health-Seeking behavior, quality of life, patients with diabetes mellitus, diabetes mellitus, diabetic clinic

\section{Introduction}

During the last twenty years the prevalence of diabetes has increased dramatically in many parts of the world and the disease is now a worldwide public health problem (Minet, 2010).

Globally, an estimated 422 million adults were living with diabetes in 2014, compared to 108 million in 1980. The global prevalence of diabetes has nearly doubled since 1980, rising from 4.7 percent to 8.5 percent in the adult population (World Health Organization, 2016). It is a major cause of morbidity, mortality, and expense wherein the effect on health and life expectancy is dramatic and costly for the patients (Dominguez, 2010).

The Philippines is one of the world's emerging diabetes hotspots. Ranked in the top 15 in the world for diabetes prevalence, and is home to more than 4 million people diagnosed with the disease - and a worryingly large unknown number who are unaware they have diabetes (International Diabetes Federation, 2012). In this country alone, diabetes is currently the leading cause of adult blindness, kidney failure and non-traumatic limb loss. It is thought that by the year 2025 , up to 8 million will be affected by the disease (Department of Health, 2012).

Health-seeking behavior is described by Harris and Guten (1979 cited by Quinn, Johnson, Poon, Martin, \& Richardson, 1997) as any behavior of an individual that promotes, protects, or maintains one's health, regardless of actual or perceived health status. Existing interventions could prevent many deaths if they presented for appropriate and timely care. However, delays in seeking appropriate care and not seeking care at all, contribute to the large number of deaths in developing countries.

Healthcare-seeking behavior of persons with diabetes has been investigated to a limited extent in developing countries, with a few exceptions (Atwine and Hjelm, 2011). Healthcare-seeking behavior is influenced by multiple factors, some of which are the 
availability, accessibility, affordability, and acceptability of the service facilities to the care recipients (Kroeger, 1983 and Rutebemberwa et al., 2013, in Atwine and Hjelm, 2011). Improving care seeking behavior could contribute significantly to reduce mortality in developing countries and that seeking prompt and appropriate care could reduce morbidity and mortality rates (World Health Organization, 2016).

Quality of life has been defined as a concept deeply influenced by subjectivity; it includes several factors, such as the perception of well-being and satisfaction of the individual in relation to their physical condition, their emotional and spiritual states, and their performance of functions, which are essential components of the human condition and involve values, attitudes and skills that impact on the quality of the participation in the various dimensions of social life (Faria, et al., 2013). In this study, quality of life is about maintaining a normal functioning and positive view of life despite changes in health status brought about by diabetes mellitus.

Diabetes can be a difficult condition to live with for many patients. The demand of self-care can be burdensome, frustrating, and overwhelming. It is connected with vascular complications, and in international and national guidelines the overall goal for the treatment of all diabetes is to prevent acute and chronic complications, while preserving a good quality of life for the patient (Wandell, 2005). Thus, knowledge concerning quality of life in diabetic patients, as well as the determinants of this, is crucial, because they may powerfully predict an individual's capacity to manage the disease and maintain long-term health and well-being.

Diabetes awareness campaigns have always been at the forefront of activities among diabetes organizations in the Philippines (Tan, 2015), however, information about diabetes care especially to those underserved regions is limited. Locally, there are no published empirical studies have been conducted on the health-seeking behavior and quality of life of patients with diabetes mellitus.

With good health-seeking and better quality of life, people with diabetes can live a long and healthy life. Everyone can play a role in reducing the impact of all forms of diabetes which can make a significant contribution to halt the rise in diabetes and improve the lives of those who are living with the disease (World Health Organization, 2016). It is important, therefore, to determine the health-seeking behavior and quality of life of patients with diabetes mellitus in Iloilo, Philippines.

\section{Methodology}

\subsection{Study Design}

This study is a descriptive-relational research using one-shot survey. The independent variable is the health seeking behavior in terms of promotive, preventive, curative, and $\mathbf{z}$ while the dependent variable is the quality of life. Data was collected only once and was appropriated for collecting descriptive information.

\subsection{Respondents}

The respondents of the study were the 45 patients with diabetes mellitus who came in for consultation in a Diabetic Resource Clinic of a Government Hospital in Iloilo, Philippines.

\subsection{Research Instrument}

The researcher-made questionnaire-checklist, a set of carefully and logically ordered questions, was used to gather the data needed for the study. The instrument was divided into three parts. The first part solicited the profile of the respondents which include the age, sex, educational attainment, work status, and family monthly income. The second part contained 
questions regarding health seeking behavior while the third part includes items that ask about the quality of life of patient with diabetes mellitus.

Health seeking behavior was measured using a 20-item questionnaire based on the promotive (the act of promoting and inquiry about diabetes mellitus), preventive (behavior which prevents or hinder from developing diabetes mellitus), curative (means of healing, curing, and relieving), and rehabilitative aspects ways of restoring to a condition of good health). The respondents were asked to fill up and answer questions by checking the best way they practice correct health seeking behavior. The following responses with the corresponding score equivalents were used: 4 points for always, 3 points for often, 2 points for sometimes, and 1 point for never. To interpret the scores, the following mean scale and interpretation were used: "Good" if the mean score is between the scale of 3.0-4.0, "Fair" if within 2.0-2.99, and "Poor" if within 1.0-1.99.

The quality of life was measured by a 21 -item questionnaire pertaining to functional status, social functioning, and psychological well-being. It was gauged using a 4-point Likert scale with the following options: 4 for always, 3 for often, 2 for sometimes, 1 for never. To determine with which the respondent was able to perform or feel certain activities and emotions in relation to all dimensions of the quality of life, the mean score was obtained. In the final analysis, it was categorized as "very satisfactory" if the mean score ranged 3.0-4.0, "satisfactory" if the mean score ranged to 2.0-2.99 and "unsatisfactory" if the mean score ranged 1.0- 1.99 .

The instrument was presented to three experts for content validation. Suggestions, ideas, and comments were noted and were taken into consideration in the final revision of the research instrument. The instrument was subjected to pre-testing among the 6 patients with diabetes mellitus. The results were 0.71 for health seeking behaviors and 0.72 for quality of life. This proved that the instrument was reliable.

\subsection{Data Gathering Procedure}

Before the actual administration, permission to conduct the study was obtained from the Chief of Hospital and Head of Diabetes Resource Clinic. The instrument was personally administered and an interview was made to those who have difficulty in answering the research instrument. After which, immediate verification was done for completion of the data. The data were classified, tallied, tabulated, analyzed, and interpreted.

\subsection{Ethical Considerations}

Consent from the participants was secured prior to data gathering. The consent indicated that the respondents' confidentiality and privacy as a participant shall be highly maintained, and that the results shall be used for research purposes only.

\subsection{Data Analysis}

The data gathered was subjected to appropriate descriptive and inferential treatment using the Statistical Package for Social Sciences (SPSS).

For descriptive data analysis, the frequency distribution and mean were used to describe the characteristics of the respondent's age, sex, educational attainment, work status, and family monthly income.

Pearson's $r$ was used for inferential analysis.

\section{Results and Discussions}

\subsection{The Profile of the Respondents}

The respondents of this study are described in terms of their age, sex, educational attainment, work status, and family monthly income. The data are shown in Table 1. 
Age and Sex. More than two-thirds (68.9 percent) of the respondents were above fiftyone years old. Less than one-third (31.1 percent) of them were below fifty years old. In terms of sex, two-thirds (66.7 percent) of the respondents were females. One-third (33.3 percent) were males. This connotes that most of the respondents are female.

Educational Attainment. More than one-half (53.3 percent) of the respondents have attained college education. Less than one-third (31.1 percent) have attained high school education while 15.6 percent have reached only elementary education. The data further show that the respondents were college educated.

Work Status. More than three-fifths of the respondents (62.2 percent) are working while less than two-fifths (37.8 percent) of them are not working.

Family Monthly Income. The data show that less than one-half of the respondents (44.5 percent) have a monthly income of above ten thousand pesos. One third of them (33.3 percent) have an income of five thousand to ten thousand pesos while more than onefifths ( 22.2 percent) of them have an income of below five thousand pesos. This connotes that most of them have an income of above ten thousand pesos $(\mathrm{PhP})$.

Table 1. Distribution of Respondents According to Age, Sex, Educational Attainment, Work Status, and Family Monthly Income

\begin{tabular}{|c|c|c|}
\hline Profile & Frequency & Percentage \\
\hline I. Entire Group & 45 & 100.0 \\
\hline \multicolumn{3}{|l|}{ II. Age } \\
\hline 51 years old and above & 31 & 68.9 \\
\hline 50 years old and below & 14 & 31.1 \\
\hline Total & 45 & 100.0 \\
\hline \multicolumn{3}{|l|}{ III. Sex } \\
\hline Male & 15 & 33.3 \\
\hline Female & 30 & 66.7 \\
\hline Total & 45 & 100.0 \\
\hline \multicolumn{3}{|l|}{ IV. Educational Attainment } \\
\hline College Education Level & 24 & 53.3 \\
\hline High School Education Level & 14 & 31.1 \\
\hline Elementary Education Level & 7 & 15.6 \\
\hline Total & 45 & 100.0 \\
\hline \multicolumn{3}{|l|}{ V. Work Status } \\
\hline Working & 28 & 62.2 \\
\hline Not Working & 17 & 37.8 \\
\hline Total & 45 & 100.0 \\
\hline \multicolumn{3}{|l|}{ VI. Family Monthly Income } \\
\hline Above 10,000 & 20 & 44.5 \\
\hline $5,000-10,000$ & 15 & 33.3 \\
\hline Below 5,000 & 10 & 22.2 \\
\hline Total & 45 & 100.0 \\
\hline
\end{tabular}

\subsection{Promotive, Preventive, Curative, and Rehabilitative Health-Seeking Behaviors}

In terms of promotive aspect, majority of the respondents discussed diabetes mellitus with co-workers, family, and relatives (82.2 percent). More than three-fifths (64.4 
percent) of them often read updated guidelines that provide new strategies in the treatment and management of diabetes mellitus. From time to time, more than one-half $(60.0$ percent) of the respondents have attended seminars, meetings, lecture- discussions about diabetes mellitus. Further, one-tenths of the respondents (11.1 percent) did not asked about the treatment and management of diabetes mellitus.

In the preventive aspect, majority avoided smoking and drinking of alcoholic beverages (77.8 percent). More than one-half (51.1 percent) complied with the balanced diet prescribed by the physician. Further, more than one-third had eaten fruits and vegetables once to three times a week (35.6 percent and 35.6 percent, respectively). In addition, it was also noted that less than one-half ( 48.9 percent) performed exercise such as walking and jogging once to three times a week. Surprisingly, a little more than twothirds of them (68.9 percent) had never been engaged in complementary and alternative medicine such as yoga and herbal medicines.

In the curative aspect, majority of them were taking the medications (95.6 percent), following physician's instructions about correct monitoring of blood sugar (73.3 percent), and visiting the doctor immediately for any untoward signs and symptoms of diabetes mellitus (64.4 percent). Moreover, less than three-fourths of them often followed physician's instructions regarding diabetic diet (71.1 percent). Along this vein, more than one-half of them subjected for laboratory test as advice by the physician (57.8 percent).

In the rehabilitative aspect, most of them joined diabetes support group (91.1 percent) and they visited diabetes center (86.7 percent). Oftentimes, less than three-fourths (71.1 percent) seek immediate health care if the manifestations of diabetes mellitus becomes complicated. Only 46.7 percent promoted positive attitude in dealing about managing of diabetes mellitus treatment.

\section{Table 2. Distribution of Respondents According to Promotive and} Preventive Health-Seeking Behaviors

\begin{tabular}{|c|c|c|c|c|c|c|c|c|c|c|}
\hline \multirow{2}{*}{ Health-Seeking Behaviors } & \multicolumn{2}{|c|}{ Always } & \multicolumn{2}{|c|}{ Often } & \multicolumn{2}{|c|}{ Sometimes } & \multicolumn{2}{|c|}{ Never } & \multicolumn{2}{|c|}{ Total } \\
\hline & $\mathbf{f}$ & $\%$ & $\mathbf{f}$ & $\%$ & f & $\%$ & $\mathbf{f}$ & $\%$ & f & $\%$ \\
\hline \multicolumn{11}{|l|}{ Promotive Aspect } \\
\hline $\begin{array}{l}\text { 1. Ask information on the treatment } \\
\text { and management of diabetes }\end{array}$ & 18 & 40.0 & 9 & 20.0 & 13 & 28.9 & 5 & 11.1 & 45 & 100 \\
\hline $\begin{array}{l}\text { mellitus. } \\
\text { 2. Attend seminars, meetings, lecture- }\end{array}$ & 3 & 6.7 & 15 & 33.3 & 27 & 60.0 & 0 & 0.0 & 45 & 100 \\
\hline $\begin{array}{l}\text { discussions about diabetes mellitus. } \\
\text { 3. Read updated guidelines that } \\
\text { provide new strategies in the }\end{array}$ & 10 & 22.2 & 29 & 64.4 & 6 & 13.3 & 0 & 0.0 & 45 & 100 \\
\hline $\begin{array}{l}\text { treatment and management of } \\
\text { diabetes. }\end{array}$ & 4 & 8.9 & 18 & 40.0 & 23 & 51.1 & 0 & 0.0 & 45 & 100 \\
\hline $\begin{array}{l}\text { 4. Read magazines, journals, leaflets, } \\
\text { to be aware of DM issue. } \\
\text { 5. Discuss diabetes mellitus with my } \\
\text { co-workers, family, and relatives. }\end{array}$ & 37 & 82.2 & 7 & 15.6 & 1 & 2.2 & 0 & 0.0 & 45 & 100 \\
\hline Preventive Aspect & 13 & 28.9 & 16 & 35.6 & 16 & 35.6 & 0 & 0.0 & 45 & 100 \\
\hline $\begin{array}{l}\text { 1. Eat fruits and vegetables regularly. } \\
\text { 2. Perform exercise regularly } \\
\text { (walking, jogging, etc.). }\end{array}$ & 4 & 8.9 & 12 & 26.7 & 22 & 48.9 & 7 & 15.6 & 45 & 100 \\
\hline $\begin{array}{l}\text { 3. Smoking and drinking of } \\
\text { alcoholic beverages are avoided. }\end{array}$ & 35 & 77.8 & 10 & 22.2 & 0 & 0.0 & 0 & 0.0 & 45 & 100 \\
\hline $\begin{array}{l}\text { 4. Engage in complementary and } \\
\text { alternative medicine (yoga, herbal } \\
\text { medicines, etc). }\end{array}$ & 6 & 13.3 & 1 & 2.2 & 7 & 15.6 & 31 & 68.9 & 45 & 100 \\
\hline $\begin{array}{l}\text { 5. Comply with the well-balanced diet } \\
\text { prescribed by the physician. }\end{array}$ & 18 & 40.0 & 23 & 51.1 & 4 & 8.9 & 0 & 0.0 & 45 & 100 \\
\hline
\end{tabular}


Table3. Distribution of Respondents According to Curative and Rehabilitative Health- Seeking Behaviors

\section{Health-Seeking Behaviors}

Always Often Sometimes Never Total

$\begin{array}{llllllllll}\text { f } & \% & \text { f } & \% & \text { f } & \% & \text { f } & \% & \text { f } & \%\end{array}$

Curative Aspect

1. Visit the doctor immediately for any untoward signs and symptoms and comply all the recommendations.

2. Take my medicines religiously as prescribed by the doctor.

3. Subject myself for laboratory test as per advice by the physician.

4. Follow physician's instructions about correct monitoring of blood sugar (CBG).

5. Follow physician's instructions regarding diabetic diet.

$\begin{array}{cccccccccc}29 & 64.4 & 16 & 35.6 & 0 & 0.0 & 0 & 0.0 & 45 & 100 \\ & & & & & & & & & \\ 43 & 95.6 & 2 & 4.4 & 0 & 0.0 & 0 & 0.0 & 45 & 100 \\ 15 & 33.3 & 26 & 57.8 & 4 & 8.9 & 0 & 0.0 & 45 & 100 \\ 33 & 73.3 & 7 & 15.6 & 5 & 11.1 & 0 & 0.0 & 45 & 100 \\ & & & & & & & & & \\ 13 & 28.9 & 32 & 71.1 & 0 & 0.0 & 0 & 0.0 & 45 & 100 \\ & & & & & & & & & \\ & & & & & & & & & \\ 39 & 86.7 & 6 & 13.3 & 0 & 0.0 & 0 & 0.0 & 45 & 100 \\ 24 & 53.3 & 21 & 46.7 & 0 & 0.0 & 0 & 0.0 & 45 & 100 \\ & & & & & & & & & \\ 20 & 44.4 & 17 & 37.8 & 8 & 17.8 & 0 & 0.0 & 45 & 100 \\ & & & & & & & & & \\ 41 & 91.1 & 2 & 4.4 & 2 & 4.4 & 0 & 0.0 & 45 & 100 \\ 13 & 28.9 & 32 & 71.1 & 0 & 0.0 & 0 & 0.0 & 45 & 100\end{array}$

\section{Rehabilitative Aspect}

1. Visit the Diabetes Center/Clinic.

2. Provide positive attitude in dealing with managing of diabetes treatment.

3. Participate in programs and activities such as Diabetes month

4. Join Diabetes support group.

5. Seek immediate health care if manifestations of DM become complicated.

\subsection{Level of Health-Seeking Behavior in terms of Promotive, Preventive, Curative, and Rehabilitative Aspects}

Based on the data in Table 4, the promotive $(M=2.96)$ and preventive $(M=2.78)$ aspects showed fair health-seeking behaviors while good seeking behaviors were noted to the curative $(\mathrm{M}=3.55)$ and rehabilitative $(\mathrm{M}=3.56)$ aspects. The overall mean score was good $(\mathrm{M}=3.21)$.

Table 4. Distribution of Respondents According to the Level of Health Seeking Behaviors in Terms of Promotive, Preventive, Curative, and Rehabilitative Aspects

\begin{tabular}{lcc}
\hline Health-Seeking Behaviors & Mean & Interpretation \\
\hline Promotive & 2.96 & Fair \\
Preventive & 2.78 & Fair \\
Curative & 3.55 & Good \\
Rehabilitative & 3.56 & Good \\
Over-all & 3.21 & Good \\
\hline
\end{tabular}




\subsection{The Quality of Life}

The top five quality of life which patients with diabetes mellitus have been able to function appropriately and independently were brushing of teeth, bathing the whole body, and praying and going to church, hoping for a better future, and helping others (95.6 percent, 93.3 percent, 84.4 percent, 80.0 percent, and 77.8 percent, respectively). The level of quality of life of the diabetics was satisfactory $(\mathrm{M}=2.85)$.

The result was supported by the findings of Manjunath, et al., (2014) that diabetes does impair the quality of life, but to a lesser extent. On the other hand, however, Spasić, et al., (2014) have found that patients with type 2 diabetes have a lower quality of life in all aspects (physical and mental health components).

Table 5. Distribution of Respondents According to their Quality of Life

\begin{tabular}{|c|c|c|c|c|c|c|c|c|c|c|}
\hline \multirow[b]{2}{*}{ Quality of Life } & \multicolumn{2}{|c|}{ Always } & \multicolumn{2}{|c|}{ Often } & \multicolumn{2}{|c|}{ Sometimes } & \multicolumn{2}{|c|}{ Never } & \multicolumn{2}{|c|}{ Total } \\
\hline & $\mathbf{f}$ & $\%$ & $\mathbf{f}$ & $\%$ & $\mathbf{f}$ & $\%$ & $\mathbf{f}$ & $\%$ & $\mathbf{f}$ & $\%$ \\
\hline 1. I can bathe my whole body. & 42 & 93.3 & 2 & 4.4 & 2 & 2.2 & 0 & 0.0 & 45 & 100 \\
\hline 2. I cannot perform exercise daily. & 29 & 64.4 & 12 & 26.7 & 2 & 4.4 & 2 & 4.4 & 45 & 100 \\
\hline $\begin{array}{l}\text { 3. I can perform my usual activities at } \\
\text { work and at home. }\end{array}$ & 27 & 60.0 & 11 & 24.4 & 7 & 15.6 & 0 & 0.0 & 45 & 100 \\
\hline 4. I am eating well. & 15 & 33.3 & 24 & 53.3 & 6 & 13.3 & 0 & 0.0 & 45 & 100 \\
\hline 5. I cannot sleep soundly at night. & 17 & 37.8 & 9 & 20.0 & 10 & 22.2 & 9 & 20.0 & 45 & 100 \\
\hline 6. I can brush my teeth. & 43 & 95.6 & 2 & 4.4 & 0 & 0.0 & 0 & 0.0 & 45 & 100 \\
\hline 7. I cannot take my medicine on time. & 20 & 44.4 & 16 & 35.6 & 9 & 20.0 & 0 & 0.0 & 45 & 100 \\
\hline 8. I continue to pray and go to church. & 38 & 84.4 & 7 & 15.6 & 0 & 0.0 & 0 & 0.0 & 45 & 100 \\
\hline $\begin{array}{l}\text { 9. I do not acknowledge the need for } \\
\text { emotional support from family, friends, } \\
\text { and relatives. }\end{array}$ & 23 & 51.1 & 17 & 37.8 & 3 & 6.7 & 2 & 4.4 & 45 & 100 \\
\hline $\begin{array}{l}\text { 10. I seek spiritual advice from } \\
\text { priest/minister. }\end{array}$ & 30 & 66.7 & 15 & 33.3 & 0 & 0.0 & 0 & 0.0 & 45 & 100 \\
\hline 11. I join different civic organizations. & 2 & 4.4 & 6 & 13.3 & 15 & 33.3 & 22 & 48.9 & 45 & 100 \\
\hline $\begin{array}{l}\text { 12. I do not like to talk/share with other } \\
\text { diabetic clients and help them. }\end{array}$ & 26 & 57.8 & 16 & 35.6 & 3 & 6.7 & 0 & 0.0 & 45 & 100 \\
\hline $\begin{array}{l}\text { 13. I attend social occasions and gatherings } \\
\text { when invited. }\end{array}$ & 21 & 46.7 & 17 & 37.8 & 7 & 15.6 & 0 & 0.0 & 45 & 100 \\
\hline $\begin{array}{l}\text { 14. I do not have an interest to socialize } \\
\text { with others. }\end{array}$ & 16 & 35.6 & 26 & 57.8 & 1 & 2.2 & 2 & 4.4 & 45 & 100 \\
\hline $\begin{array}{l}\text { 15. I should not be ashamed of my } \\
\text { condition. }\end{array}$ & 24 & 53.3 & 12 & 26.7 & 8 & 17.8 & 1 & 2.2 & 45 & 100 \\
\hline 16. My condition bothers me. & 15 & 33.3 & 15 & 33.3 & 9 & 20.0 & 6 & 13.3 & 45 & 100 \\
\hline 17. I have better hopes for the future. & 36 & 80.0 & 8 & 17.8 & 1 & 2.2 & 0 & 0.0 & 45 & 100 \\
\hline $\begin{array}{l}\text { 18. I am not ready for anything that can } \\
\text { happen. }\end{array}$ & 20 & 44.4 & 24 & 53.3 & 1 & 2.2 & 0 & 0.0 & 45 & 100 \\
\hline $\begin{array}{l}\text { 19. I can help others despite of my } \\
\text { situation. }\end{array}$ & 35 & 77.8 & 10 & 22.2 & 0 & 0.0 & 0 & 0.0 & 45 & 100 \\
\hline $\begin{array}{l}\text { 20. I do not have firm control over my } \\
\text { feelings and emotions. }\end{array}$ & 1 & 2.2 & 21 & 46.7 & 22 & 48.9 & 1 & 2.2 & 45 & 100 \\
\hline 21. I feel that my daily life is interesting. & 33 & 73.3 & 12 & 26.7 & 0 & 0.0 & 0 & 0.0 & 45 & 100 \\
\hline
\end{tabular}

\subsection{The Relationship between Health-Seeking Behavior and Quality of Life of Patients with Diabetes Mellitus}

Significant relationships were noted between the preventive and curative healthseeking behaviors and quality of life of patients with diabetes mellitus ( $r=.460$, 
Sig=.001 and r=.464, Sig=.001, respectively). The null hypotheses which state that there were no significant relationships between preventive and curative healthseeking behaviors and quality of life were rejected. This means that the preventive and curative health-seeking behaviors do affect the quality of life of patients with diabetic mellitus. Active seeking and appropriate care could contribute significantly in improving the functioning and well-being of patients, which further enables them to maintain a positive view and satisfaction of life in making adjustments to changes brought about by diabetes mellitus.

The promotive and the rehabilitative health-seeking behaviors did not show any significant findings $(\mathrm{r}=.115$, Sig=.451 and $\mathrm{r}=.001$, Sig=.992, respectively). The promotive and rehabilitative health-seeking behaviors do not have a significant bearing on the quality of life of patients with diabetes mellitus.

Table 6. Distribution of Respondents According to the Relationship Between Health- Seeking Behaviors and Quality of Life

\begin{tabular}{lccl}
\hline $\begin{array}{c}\text { Health-Seeking } \\
\text { Behaviors }\end{array}$ & $\begin{array}{c}\text { Quality of Life } \\
(\mathbf{r})\end{array}$ & Significance & Interpretation \\
\hline Promotive & .115 & .451 & Not Significant \\
Preventive & .460 & .001 & Significant \\
Curative & .464 & .001 & Significant \\
Rehabilitative & .001 & .992 & Not Significant \\
\hline
\end{tabular}

\section{Conclusion}

An appropriate health-seeking behavior in terms of preventive and curative aspects are important factors that could improve the quality of life of patients with diabetes mellitus. The results of the study require strategies and actions that could enhance their health-seeking behavior in the promotive and rehabilitative aspects.

\section{Conflict of Interests}

The authors declare that there is no conflict of interests regarding the publication of this paper.

\section{References}

[1] L. K. R. Minet, "Self-Management in diabetes care: the importance of self-care management intervention in chronically ill patients diagnosed with diabetes", Published doctoral dissertation, University of Southern Denmark, Odense, (2010). Accessed July 21, 2015 from http://www.ouh.dk/dwn193290.

[2] World Health Organization. Accessed August 23, 2016 from http://www.who.int/mediacentre/factsheets/fs $312 / \mathrm{en}$.

[3] R. J. Domiguez, "Health-seeking behavior of patients with diabetes mellitus in Baguio City", NLR Journal, vol. 3-4, (2010).

[4] International Diabetes Association, "Global guideline for type 2 diabetes", Accessed August 28, 2015 from http://www.idf.org/guidelines.

[5] Department of Health, Philippines, "Diabetes prevention and control program", Accessed July 1, 2015 from http://www.doh.gov.ph/diabetes-prevention-and-control-program.

[6] M. E. Quinn, M. A Johnson, L. W. Poon, P. Martin and S. M. Richardson, "Factors of nutritional healthseeking behaviors: findings from the Georgia Centenarian study”, Journal of Aging Health, vol. 9, no. 1, (1997), pp. 90-104. 
[7] K. Hjelm and F. Atwine, "Health-care seeking behavior among persons with diabetes in Uganda: an interview study”, BMC Int Health Hum Rights, vol. 11, no. 11, (2011). doi: 10.1186/1472-698X-11-11.

[8] H. Faria, V. Veras, A. Xavier, C. Teixeira, M. L. Zanetti and M. A. Santos, "Quality of life in patients with diabetes mellitus before and after their participation in an educational program", Rev. esc. enferm. USP, vol. 47, no. 2, (2013). http://dx.doi.org/10.1590/S0080-623420130002000.

[9] P. E. Wändell, "Quality of life of patients with diabetes mellitus. An overview of research in primary health care in the Nordic countries", Scand Journal of Prim Health Care, vol. 23, no. 2, (2005), pp. 6874.

[10] G. Tan, "Diabetes care in the Philippines", Annals of Global Health, vol. 81, no. 6, (2015), pp. 863-869.

[11] K. Manjunath, P. Christopher, V. Gopichandran, P. S. Rakesh, K. George and J. H. Prasad, "Quality of life of a patient with type 2 diabetes: a cross-sectional study in Rural South India", Journal of Family Med Prim Care, vol. 3, no. 4, (2014), pp. 396-399. doi:10.4103/2249-4863.148124.

[12] A. Spasić, R. V. Radovanović, A. C. Catić Đorđević, N. Stefanović and T. Cvetković, "Quality of life in type 2 diabetic patients", Scientific Journal of the Faculty of Medicine in Niš, vol. 31, no. 3, (2014), pp. 193-200. doi: 10.2478/afmnai-2014-0024.

\section{Authors}

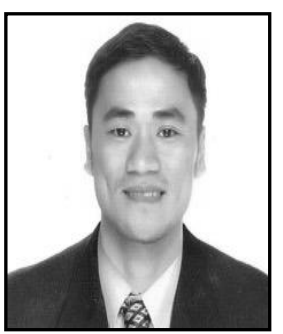

Perry Paul J. Espinosa, PhD, RN, is a Professor of Nursing in Woosong College, Daejeon, Republic of Korea. He has extensive nursing undergraduate and graduate teaching experiences. In $\mathrm{PhD}$ programs, he has developed and taught advanced qualitative research inquiry in nursing in University of St. La Salle, Bacolod City, Philippines. He has mentored Masters and $\mathrm{PhD}$ students and a panel member for various thesis and projects.

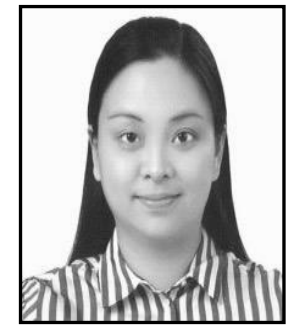

Mae Joy Penaflor- Espinosa, PhD, RN is an Assistant Professor in Woosong University, Daejeon, Republic of Korea. She had been a Lecturer in the College of Nursing, Sultan Qaboos University, Muscat, Oman. She has made significant contributions to patient care through teaching, lectures, leadership activities and professional activities both in graduate and undergraduate nursing. 
International Journal of Bio-Science and Bio-Technology

Vol.9, No.1 (2017) 